\title{
Evaluation of the diffusion capacity of calcium hydroxide pastes through the dentinal tubules
}

\section{Graziela Garrido Mori(a) Fábio Cézar Ferreira ${ }^{(b)}$ \\ Fábio Roberto de Souza Batista(c) Alessandro Mauro de Siqueira \\ Godoy(c) \\ Daniele Clapes Nunes(d)}

\footnotetext{
(a) $\mathrm{PhD}$, Professor of Integrated Clinic; (c) Graduate Student - Dental School of Adamantina, Adamantina, SP, Brazil.

(b) PhD in Physical Chemistry, Institute of Chemistry of São Carlos (IQSC), University of São Paulo, São Carlos, SP, Brazil.

(d) MSc Student in Integrated Clinic, School of Dentistry of Araçatuba, São Paulo State University, Araçatuba, SP, Brazil.
}

\begin{abstract}
This study aimed to evaluate the diffusion capacity of calcium hydroxide pastes with different vehicles through dentinal tubules. The study was conducted on 60 extracted single-rooted human teeth whose crowns had been removed. The root canals were instrumented and divided into 4 groups according to the vehicle of the calcium hydroxide paste: Group I - distilled water; Group II - propylene glycol; Group III $-0.2 \%$ chlorhexidine; Group IV - $2 \%$ chlorhexidine. After placement of the root canal dressings, the teeth were sealed and placed in flasks containing deionized water. After 1, 2, 7, 15, 30, 45 and 60 days, the $\mathrm{pH}$ of the water was measured to determine the diffusion of calcium hydroxide through the dentinal tubules. The data were recorded and statistically compared by the Tukey test. The results showed that all pastes presented a similar diffusion capacity through dentin. Group IV did not present difference compared to group I. Group II presented difference compared to the other groups, as did Group III. In conclusion, groups I and IV presented a better diffusion capacity through dentin than groups II and III; $2 \%$ chlorhexidine can be used as a vehicle in calcium hydroxide pastes.
\end{abstract}

Descriptors: Chlorhexidine; Calcium hydroxide; Dentin.
Corresponding author:

Graziela Garrido Mori

Rua Oscar de Toledo Cezar, 111 , Vila Soller

Pirapozinho - São Paulo - Brazil

CEP: 19200-000

E-mail: grazielagm@hotmail.com
Received for publication on Dec 06, 2007

Accepted for publication on May 27, 2008 


\section{Introduction}

Calcium hydroxide is the material of choice as intracanal medicament in Endodontics. ${ }^{1}$ This material was introduced by Hermann in 1920 and has been largely employed in different clinical situations since then, including the use as intracanal therapeutic agent. ${ }^{1}$

The effects of calcium hydroxide include: antimicrobial activity, ${ }^{1-4}$ capacity to limit root resorption ${ }^{5-7}$ and promotion of repair of periapical and surrounding tissues. ${ }^{1,2}$

The antimicrobial activity and capacity to limit root resorption are related to the alkalinizing action of calcium hydroxide, which in turn is a consequence of its ionization into hydroxyl ions..$^{2,4-9}$ Tronstad et al. ${ }^{8}$ (1981) suggested that calcium hydroxide in the root canals promoted an increase in $\mathrm{pH}$ on the external root surface, thus producing alkalinization of resorption areas on the root surface by diffusion of hydroxyl ions through the dentinal tubules. Another important characteristic of the dissociation of calcium hydroxide into hydroxyl ions is the ability of these ions to inactivate bacterial lipopolysaccharide (LSP), a toxin produced by gram-negative bacteria, commonly found in the root canal system. ${ }^{3}$

Thus, when applied in the root canal, calcium hydroxide should be able to diffuse through the apical foramen, secondary and accessory canals, as well as through the dentinal tubules, reaching areas of root resorption, areas contaminated by microorganisms and surrounding tissues, thereby exerting its action. ${ }^{2,8,9}$

Several liquids have been added to calcium hydroxide powder to create pastes. ${ }^{1}$ This addition aims to facilitate the use of calcium hydroxide, and improve its antimicrobial capacity, radiopacity and consistence. ${ }^{1}$ The vehicle employed in this association should allow gradual and efficient dissociation of hydroxyl ions to allow an efficient action of calcium hydroxide. ${ }^{1,2,10,11}$

Distilled water, saline, propylene glycol, anesthetic solutions, as well as other liquids, have been frequently employed as vehicles in calcium hydroxide pastes. ${ }^{1,2,9-15}$ However, the level of dissociation of calcium hydroxide into calcium and hydroxil ions depends on the vehicle employed to prepare the paste..$^{10,11,14}$ Thus, several associations have been investigated to determine the effectiveness of calcium hydroxide pastes. ${ }^{1,9-11,13-15}$

Besides allowing dissociation of the calcium hydroxide, the vehicle may increase the antimicrobial capacity of the paste. According to Heling et al. ${ }^{16}$ (1992) chlorhexidine may be used as a vehicle in an attempt to increase the antimicrobial capacity of calcium hydroxide pastes since it is effective against gram-positive and gram-negative, aerobic and facultative anaerobic microorganisms, yeasts and viruses. ${ }^{17}$

Thus, considering these aspects, this study evaluated the ability of calcium hydroxide mixed with different vehicles to diffuse through dentin.

\section{Material and Methods}

This study was conducted on 60 extracted singlerooted human teeth, with single and straight canals. The study was approved by the Institutional Review Board, Dental School of Araçatuba, São Paulo State University (UNESP - Process FOA 2006-01176).

Initially, the teeth were kept in a $10 \%$ formaldehyde solution (Farma-Ticli Indústria Farmacêutica, São Paulo, SP, Brazil). The soft tissues and dental calculus adhered to the root were eliminated with dental scalers (S.S. White Artigos Dentários LTDA., Juiz de Fora, MG, Brazil) and then the teeth were stored in a saline solution (Darrow Laboratórios S.A., Rio de Janeiro, RJ, Brazil).

The crowns were then transversally sectioned with a carborundum disc (Dentorium-International, New York, NY, USA), at the level of the cementoenamel junction.

The length of the root canals was measured by insertion of a K file \#10 (Maillefer Instruments, Ballaigues, Switzerland) with a rubber stop. When the file tip reached the apical foramen, the stop was leveled to the cervical edge of the root and the length was recorded.

The working length was established by subtracting one millimeter from the total root canal length. Biomechanical root canal preparation was performed to this limit for apical preparation up to file \#40, followed by step-back instrumentation up to 
file \#60.

The root canals were irrigated with saline solution throughout the instrumentation with the aid of a Luer-Lock syringe (Duflex - S.S. White Artigos Dentários LTDA., Rio de Janeiro, RJ, Brazil) and an irrigation canula \#30X4 (BD - Becton Dickinson Indústrias Cirúrgicas LTDA., Rio de Janeiro, RJ, Brazil).

After instrumentation, a file \#20 was inserted to the total working length for apical cleaning, and the root canal was filled with EDTA solution (Odahcam Dentsply Indústria e Comércio LTDA., Petrópolis, RJ, Brazil) for 3 minutes. After this period, the root canals were rinsed with saline solution and dried with absorbent paper points (Tanariman Industrial LTDA., Manacapuru, AM, Brazil).

Next, the teeth were randomly divided into 4 groups based on the various calcium hydroxide pastes used to fill the canals as follows:

a. Group I $(\mathrm{n}=15)$ : calcium hydroxide paste with distilled water. The paste was prepared by mixing $1 \mathrm{~g}$ of calcium hydroxide (Biodinâmica Química e Farmacêutica LTDA., Ibiporã, PR, Brazil) and $1.5 \mathrm{ml}$ of distilled water (Drogaderma, Presidente Prudente, SP, Brazil) - ( $\mathrm{pH}=12.51)$;

b. group II $(\mathrm{n}=15)$ : calcium hydroxide paste with propylene glycol. The paste was prepared by mixing $1 \mathrm{~g}$ of calcium hydroxide and $2 \mathrm{ml}$ of propylene glycol (Drogaderma, Presidente Prudente, SP, Brazil) - ( $\mathrm{pH}=12.64)$;

c. group III $(\mathrm{n}=15)$ : calcium hydroxide paste with $0.2 \%$ chlorhexidine. The paste was prepared by mixing $1 \mathrm{~g}$ of calcium hydroxide and $1 \mathrm{ml}$ of a $0.2 \%$ chlorhexidine solution (Drogaderma, Presidente Prudente, SP, Brazil) - $(\mathrm{pH}=12.31)$;

d. group IV $(\mathrm{n}=15)$ : calcium hydroxide paste with $2 \%$ chlorhexidine. The paste was prepared by mixing $1 \mathrm{~g}$ of calcium hydroxide and $1.5 \mathrm{ml}$ of a $2 \%$ chlorhexidine solution (Drogaderma, Presidente Prudente, SP, Brazil) - ( $\mathrm{pH}=12.57)$.

Complete filling of the root canals was checked by the overflow of solution through the apical foramen and reflux through the root canal opening. After complete filling of the root canals, their openings were sealed with temporary cement (Cimpat-Septodont, Louisville, CO, USA). The apical foramen and root canal openings (over the temporary cement) were sealed with epoxi resin (Araldite ${ }^{\circledR}$-Maxepoxi Industrial e Comercial Ltda., São Paulo, SP, Brazil). The teeth were then placed in flasks containing $30 \mathrm{ml}$ of deionized water $(\mathrm{pH}=6.17)$ and kept in an oven at $37^{\circ} \mathrm{C}$, with $100 \%$ humidity.

After 1, 2, 7, 15, 30, 45 and 60 days, the $\mathrm{pH}$ values of the solutions in the flasks were measured with the aid of a $\mathrm{pH}$ meter (Hanna Instruments Brasil Copyright, São Paulo, SP, Brazil). The pH meter was calibrated with standardized solutions at $\mathrm{pH} 4.0$ and 7.0. Fifteen measurements were performed for each group/period. For each measurement, the electrode of the $\mathrm{pH}$ meter was carefully rinsed with deionized water and dried with absorbent paper to eliminate any residues that might interfere with the measurements.

The data was recorded in tables and the differences between the study groups and study periods were statistically analyzed by the Tukey test, at a significance level of $5 \%$.

\section{Results}

Graph 1 presents the variation in $\mathrm{pH}$ with time, for the different pastes. The values indicate the means obtained for each period, considering the 15 measurements obtained for each group. As evidenced by these data, Group II presented the lowest $\mathrm{pH}$ values.

In Group I, there was constant diffusion of paste through the dentinal tubules, without statistically

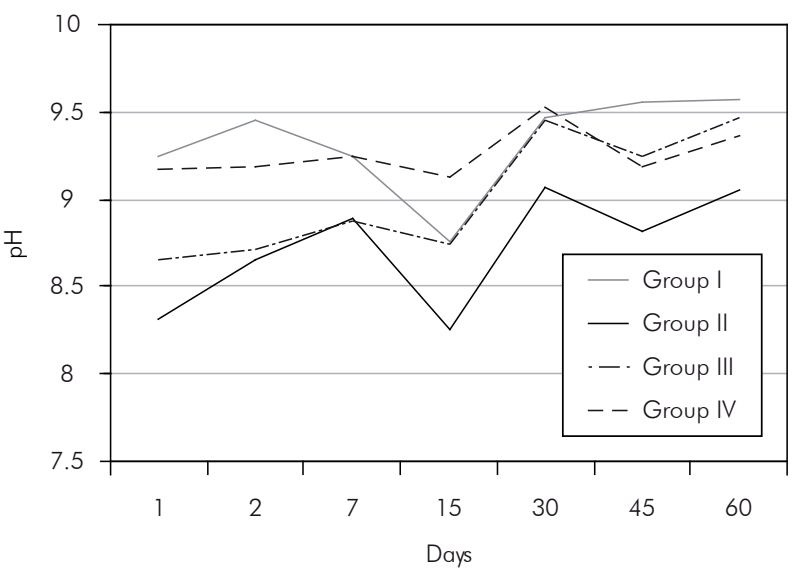

Graph 1 - Variation of mean $\mathrm{pH}$ values according to the study periods, for the different study groups. 
significant differences in $\mathrm{pH}$ values with time for this group. The same was observed for Group IV, without statistically significant differences between the study periods.

Group II exhibited statistically significant variations in $\mathrm{pH}$ with time $(\mathrm{p}<0.05)$. At 1 and 2 days, the mean $\mathrm{pH}$ was low (8.32 and 8.66 , respectively). At 7 days, there was a significant increase in $\mathrm{pH}$ for this group $(\mathrm{p}<0.05)$. Despite the $\mathrm{pH}$ reduction at 15 days (Graph 1), there was no significant difference compared to the study periods of 7, 30, 45 and 60 days. This indicated stagnation in the release of hydroxyl ions after 7 days.

Group III presented an increase in $\mathrm{pH}$ with time, since the mean $\mathrm{pH}$ recorded for this group was 8.66 at the onset (day 1) and 9.47 at study completion (day 60). This was confirmed by the statistical test, which demonstrated significant differences between the study periods of $1,2,7$ and 15 days compared to 30, 45 and 60 days.

Statistical comparison revealed that Groups I and IV did not present significant differences. Group II presented difference compared to the other groups, as did Group III $(\mathrm{p}<0.05)$.

\section{Discussion}

The diffusion of calcium hydroxide through dentinal tubules has been evaluated in several studies. . $, 5,8,10-15$ The diffusion through dentinal tubules, apical foramen, secondary and accessory canals allows the calcium hydroxide to reach regions contaminated by microorganisms, areas of root resorption and surrounding tissues, promoting its antimicrobial and anti-resorptive action..$^{2,8,9}$

The vehicles employed in calcium hydroxide pastes influence their biological and antimicrobial properties and may also affect the diffusion capacity of calcium hydroxide. . $^{1,2,8-15}$

Estrela et al..$^{14}$ (1995) described that distilled water allows the fastest and most significant dissociation of the calcium hydroxide paste, being the vehicle of choice. Conversely, Simon et al. ${ }^{11}$ (1995) recommended propylene glycol as the best vehicle. This may be related to the antimicrobial capacity and good consistence of propylene glycol, producing a viscous paste, which is easy to work and presents high quality. ${ }^{1,11}$ Currently, these two substances are the most employed in calcium hydroxide pastes.

Due to the antimicrobial effectiveness of chlorhexidine, it has been suggested as a vehicle for calcium hydroxide pastes. ${ }^{16}$ Some authors evaluated the antimicrobial activity of the association of calcium hydroxide and chlorhexidine, which revealed that this association was effective against microorganisms. ${ }^{18-21}$

The activity of chlorhexidine is related to the bonding of its cationic molecule to the bacterial cell wall (anionic) by an electrostatic reaction. The bacterial wall presents changes and the osmotic balance is lost, leading to its rupture. ${ }^{17}$ Chlorhexidine is bacteriostatic at low concentrations and bactericidal at high concentrations. ${ }^{17}$

This explains the intention to associate chlorhexidine and calcium hydroxide for utilization as an intracanal medicament. Several concentrations of chlorhexidine have been evaluated in microbiological tests; thus, two different concentrations of chlorhexidine $(0.2 \%$ and $2 \%)$ were used in this study. These associations were compared to pastes with distilled water or propylene glycol.

The calcium hydroxide paste with distilled water (Group I) presented constant diffusion through the dentinal tubules. The $\mathrm{pH}$ values were high (above 9.0) since the first day of analysis and throughout the study period. The studies of Estrela et al. ${ }^{14}$ (1995) and Zmener et al. ${ }^{9}$ (2007) also demonstrated an effective dissociation of calcium hydroxide paste with distilled water in the first hours after preparation. The $\mathrm{pH}$ values in these studies were also constant with time, similarly to the present results.

The outcomes of the present study demonstrate differences between the utilization of distilled water and propylene glycol. The $\mathrm{pH}$ values were higher with the utilization of distilled water, which indicates a higher diffusion of the paste through the dentinal tubules, as observed by Estrela et al..$^{14}$ (1995) and Andrade Ferreira et al. ${ }^{15}$ (2004). A clinical evaluation of calcium hydroxide pastes revealed that distilled water was more effective than propylene glycol. ${ }^{22}$ These data agree with the $\mathrm{pH}$ values observed in this study.

The comparison of pastes containing chlorhexi- 
dine revealed that the concentration influenced the diffusion of the calcium hydroxide paste. The $2 \%$ chlorhexidine allowed higher diffusion than $0.2 \%$ chlorhexidine $(\mathrm{p}<0.05)$ until day 15 . Therefore, the association of calcium hydroxide with $2 \%$ chlorhexidine performed better than that with $0.2 \%$ chlorhexidine.

The results also revealed no difference between the utilization of distilled water and $2 \%$ chlorhexidine as vehicles. One interesting factor was the higher viscosity and easier preparation of the paste with

\section{References}

1. Fava LR, Saunders WP. Calcium hydroxide pastes: classification and clinical indications. Int Endod J. 1999 Aug;32(4):25782.

2. Duarte MA, Demarchi AC, Giaxa MH, Kuga MC, Fraga SC, de Souza LC. Evaluation of $\mathrm{pH}$ and calcium ion release of three root canal sealers. J Endod. 2000 Jul;26(7):389-90.

3. Safavi KE, Nichols FC. Alteration of biological properties of bacterial lipopolysaccharide by calcium hydroxide treatment. J Endod. 1994 Mar;20(3):127-9.

4. Siqueira JF, Lopes HP. Mechanisms of antimicrobial activity of calcium hydroxide: a critical review. Int Endod J. 1999 Sep;32(5):361-75.

5. Trope M, Moshonov J, Nissan R, Buxt P, Yesilsoy C. Short vs. Long-term calcium hydroxide treatment of established inflammatory root resorption in replanted dog teeth. Endod Dent Traumatol. 1995 Jun;11(3):124-8.

6. Trope M, Yesilsoy C, Koren L, Moshonov J, Friedman S. Effect of different endodontic treatment protocols on periodontal repair and root resorption of replanted dog teeth. J Endod. 1992 Oct;18(10):492-6.

7. Vanderas AP. Effects of intracanal medicaments on inflammatory resorption or occurrence of ankylosis in mature traumatized teeth: a review. Endod Dent Traumatol. 1993;9(5):17584.

8. Tronstad L, Andreasen JO, Hasselgren G, Kristerson L, Riis I. $\mathrm{pH}$ changes in dental tissues after root canal filling with calcium hydroxide. J Endod. 1981 Jan;7(1):17-21.

9. Zmener O, Pameijer CH, Banegas G. An in vitro study of the $\mathrm{pH}$ of three calcium hydroxide dressing materials. Dent Traumatol. 2007 Feb;23(1):21-5.

10. Pacios MG, de la Casa ML, de los Angeles Bulacio M, Lópes ME. Calcium hydroxide's association with different vehicles: in vitro action on some dentinal components. Oral Surg Oral Med Oral Pathol Oral Radiol Endod. 2003 Jul; 96(1):96101.

11. Simon ST, Bhat KS, Francis L. Effect of four vehicles on the $\mathrm{pH}$ of calcium hydroxide and the release of calcium ion. Oral Surg chlorhexidine compared to that with distilled water.

\section{Conclusions}

According to the present results, groups I and IV presented a better diffusion capacity through the dentin than groups II and III. The $2 \%$ chlorhexidine solution was efficient as a vehicle in the calcium hydroxide paste. This paste could be an alternative option as root canal dressing in Endodontics. Nevertheless, the biocompatibility of $2 \%$ chlorhexidine should be analyzed before its use is indicated.

Oral Med Oral Pathol Oral Radiol Endod. 1995;80(4):45964.

12. Azabal-Arroyo M, Menasalvas-Ruiz G, Martín-Alonso J, Arroquia JJ, Vega-del Barrio JM. Loss of hydroxyl ions from gutta-percha points with calcium hydroxide in their composition: an in vivo study. J Endod. 2002 Oct; 28(10):697-8.

13. Çalt S, Serper A, Özçelik B, Dalat MD. pH changes and calcium ion diffusion from calcium hydroxide dressing materials through root dentin. J Endod. 1999 May;25(5):329-31.

14. Estrela C, Sydney GB, Pesce HF, Felippe Júnior O. Dentinal diffusion of hydroxyl ions of various calcium hydroxide pastes. Braz Dent J. 1995;6(1):5-9.

15. de Andrade Ferreira FB, Silva e Souza Pde A, do Vale MS, de Moraes IG, Granjeiro JM. Evaluation of $\mathrm{pH}$ levels and calcium ion release in various calcium hydroxide endodontic dressings. Oral Surg Oral Med Oral Pathol Oral Radiol Endod. 2004 Mar;97(3):388-92.

16. Heling I, Sommer M, Steinberg D, Friedman M, Sela MN. Microbiological evaluation of the efficacy of chlorhexidine in a sustained-release device for dentine sterilization. Int Endod J. 1992 Jan;25(1):15-9.

17. Silva LA, Leonardo MR, Assed S, Tanomaro Filho M. Histological study of the effect of some irrigating solutions on bacterial endotoxin in dogs. Braz Dent J. 2004;15(2):10914.

18. Almyroudi A, Mackenzie D, McHugh S, Saunders WP. The effectiveness of various disinfectants used as endodontic intracanal medications: an in vitro study. J Endod. 2002 Mar;28(3):163-7.

19. Ercan E, Dalli M, Dülgergil CT. In vitro assessment of the effectiveness of chlorhexidine gel and calcium hydroxide paste with chlorhexidine against Enterococcus faecalis and Candida albicans. Oral Surg Oral Med Oral Pathol Oral Radiol Endod. 2006 Aug;102(2):e27-31.

20. Evans MD, Baumgartner JC, Khemaleelakul SU, Xia T. Efficacy of calcium hydroxide: chlorhexidine paste as an intracanal 
- Evaluation of the diffusion capacity of calcium hydroxide pastes through the dentinal tubules

medication in bovine dentin. J Endod. 2003 May;29(5):3389.

21. Gomes BP, Vianna ME, Sena NT, Zaia AA, Ferraz CC, de Souza Filho FJ. In vitro evaluation of the antimicrobial activity of calcium hydroxide combined with chlorhexidine gel used as intracanal medicament. Oral Surg Oral Med Oral Pathol Oral Radiol Endod. 2006 Oct;102(4):544-50.

22. Pacios MG, La Casa ML, Bulacio MLB, López ME. Influence of different vehicles on the $\mathrm{pH}$ of calcium hydroxide pastes. J Oral Sci. 2004;46(2):107-11. 